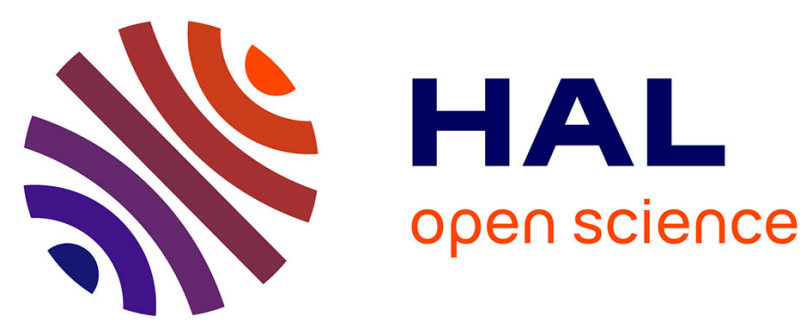

\title{
Antitumoral activity of camptothecin-loaded nanoparticles in 9L rat glioma model
}

Y. Cirpanli, Emilie Allard-Vannier, Catherine Passirani-Malleret, E. Bilensoy, Laurent Lemaire, S. Calis, Jean-Pierre Benoît

\section{- To cite this version:}

Y. Cirpanli, Emilie Allard-Vannier, Catherine Passirani-Malleret, E. Bilensoy, Laurent Lemaire, et al. Antitumoral activity of camptothecin-loaded nanoparticles in 9L rat glioma model. International Journal of Pharmaceutics, 2011, 403 (1-2), pp.201-6. 10.1016/j.ijpharm.2010.10.015 . hal-03171854

\section{HAL Id: hal-03171854 \\ https://univ-angers.hal.science/hal-03171854}

Submitted on 17 Mar 2021

HAL is a multi-disciplinary open access archive for the deposit and dissemination of scientific research documents, whether they are published or not. The documents may come from teaching and research institutions in France or abroad, or from public or private research centers.
L'archive ouverte pluridisciplinaire HAL, est destinée au dépôt et à la diffusion de documents scientifiques de niveau recherche, publiés ou non, émanant des établissements d'enseignement et de recherche français ou étrangers, des laboratoires publics ou privés. 


\title{
Antitumoral activity of camptothecin-loaded nanoparticles in 9L rat glioma model
}

\author{
Yasemin Çırpanlı $^{\mathrm{a}}$, Emilie Allard ${ }^{\mathrm{b}}$, Catherine Passirani ${ }^{\mathrm{b}}$, Erem Bilensoy ${ }^{\mathrm{a}}$, \\ Laurent Lemaire $^{\mathrm{b}}$, Sema Çalış̧,*, Jean-Pierre Benoit ${ }^{\mathrm{b}}$ \\ a Hacettepe University Faculty of Pharmacy, Department of Pharmaceutical Technology, 06100 Ankara, Turkey \\ ' INSERM U646, Université d'Angers, 49100 Angers, France
}

\section{A R T I C L E I N F O}

\section{Article history:}

Received 14 June 2010

Received in revised form

30 September 2010

Accepted 9 October 2010

Available online 15 October 2010

\section{Keywords:}

Camptothecin

Amphiphilic cyclodextrin

Poly(lactide-co-glycolide)

Poly- $\varepsilon$-caprolactone

Nanoparticle

9L glioma model

\begin{abstract}
A B S T R A C T
Camptothecin (CPT), a plant alkaloid, is a potent anticancer drug in cell culture studies but it is clinically inactive due to rapid hydrolysis under physiological conditions. The drug exists in two forms depending on the $\mathrm{pH}$ value, an active lactone form at $\mathrm{pH}$ below 5 and an inactive carboxylate form at basic $\mathrm{pH}$ and this is a reversible reaction. In this study, nanoparticulate delivery systems were developed with either amphiphilic cyclodextrins, poly(lactide-co-glycolide) or poly- $\varepsilon$-caprolactone in order to maintain the active lactone form and prevent the drug from hydrolysis. All nanoparticles were prepared with nanoprecipitation technique. Mean particle sizes were $130-280 \mathrm{~nm}$ and surface charges were negative. The encapsulation efficiency was significantly higher for amphiphilic cyclodextrin nanoparticles when compared to polymeric nanoparticles. Nanoparticle formulations based on cyclodextrins showed a controlled release profile extended up to 12 days. 6 -O-Capro- $\beta$-cyclodextrin $(1.44 \mu \mathrm{g} / 60 \mu \mathrm{L}$ CPT) and concentrated 6-O-Capro- $\beta$-cyclodextrin $(2.88 \mu \mathrm{g} / 60 \mu \mathrm{LCPT})$ nanoparticles significantly modified the growth or lethality of the 9L gliomas, since the median survival time was 26 days for the untreated group and between 27 and 33 days for amphiphilic cyclodextrin nanoparticle groups. These results indicate that, CPT-loaded amphiphilic cyclodextrin nanoparticles may provide a promising carrier system for the effective delivery of CPT in comparison to polymeric analogues.
\end{abstract}

(C) 2010 Elsevier B.V. All rights reserved.

\section{Introduction}

Camptothecin (CPT) is a potent anticancer drug. Anticancer activity of this drug is directed against a broad spectrum of cancers, such as colon, breast, ovarian, and lung cancers (Hatefi and Amsden, 2002). CPT and its analogs inhibit DNA topoisomerase I, an enzyme required for replication and transcription of DNA. This subsequent stabilizing of DNA topoisomerase complex results in apoptosis of cancer cells (Rothenberg, 1997). Although CPT has been demonstrated to be very effective against a variety of tumors and cancer cell types in cell culture studies, clinical studies have come to a dead-end due to clinical inefficacy and undesired side-effects.

Clinical application of CPT against cancer is limited by its formulation and delivery problems. CPT is extremely insoluble in water $(<1 \mathrm{mg} / \mathrm{mL}$ ) and has a chemically unstable E-ring (lactone function). This lactone function is essential for antitumor activity but in plasma the $\mathrm{pH}$ favors the inactive carboxylate form. This form has no clinical activity, a significantly lower solubility and higher toxicity (Berrada et al., 2005; Kunii et al., 2007; Tung et al., 2003).

\footnotetext{
* Corresponding author. Tel.: +90 31230512 41; fax: +90 3123100906.

E-mail address: scalis@hacettepe.edu.tr (S. Çalış).
}

The hydrolysis reaction of CPT under physiological conditions is seen in Fig. 1.

Gliomas are the most common types of brain tumors. Treatment of malignant gliomas represents important challenges in oncology. The combination of surgery, radiation and chemotherapy is needed and median survivals of less than one year are reported with this treatment schedule (Gralow et al., 2008). A major handicap in treating malignant glioma with systemic chemotherapy is the blood brain barrier. The blood brain barrier restricts the delivery of systemically administered agents for treating brain tumors so efficient systemic drug delivery throughout the tumor is very difficult. Convection enhanced delivery (CED) is a local regional drug delivery technique. It uses a pressure driven bulk-flow process to distribute drugs. CED technique was introduced in 1994 and it is a method to bypass the blood-brain barrier and enhance distribution of therapeutic agents by direct delivery of drugs into brain tissue and brain tumors. It is a promising technique for brain tumor therapy, and safety and feasibility of CED have been established (Allard et al., 2009a).

Cyclodextrins are cyclic oligosaccharides containing at least 6 D-(+) glucopyranose units which are attached by $\alpha-(1,4)$ glucosidic bonds. They have lipophilic inner cavities and hydrophilic outer surfaces. They are capable of interacting with a large variety 


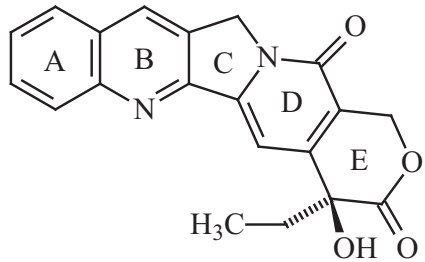

Lactone form

Active
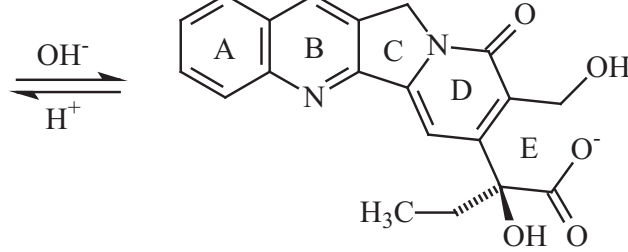

Carboxylate form

Inactive

Fig. 1. Camptothecin structure and equilibrium between active lactone form and inactive carboxylate form.

of guest molecules and to form noncovalent inclusion complexes. They have been widely used for the formulation of drugs with bioavailability problems resulting from poor aqueous solubility, poor stability (hydrolytic or photodegradation, etc.) and severe side effects (Brewster and Loftsson, 2007; Uekama et al., 1998; Loftsson and Duchene, 2007).

Amphiphilic cyclodextrins are chemical derivatives of natural cyclodextrins. $\beta$ - and $\gamma$-cyclodextrin are obtained by grafting aliphatic chains to the primary and/or secondary face of the cyclodextrin glucopyranose unit. These cyclodextrin derivatives are of interest for pharmaceutical applications in view of their ability to self-organize in water to form micelles and nano-aggregates, which is a result of their altered surface properties and their general amphiphilic characteristic. Amphiphilic cyclodextrins have the ability to form supramolecular aggregates in the form of nanoparticles. They form stable nanospheres and nanocapsules with and without the presence of surfactants and have shown high drugloading capacity with favorable release properties (Bilensoy, 2008).

CPT-loaded cyclodextrin nanoparticles were reported to be promising delivery systems for cancer therapy and in vivo behavior of these nanoparticulate carriers for CPT was evaluated in animal models (Cirpanli et al., 2009). Thus, the antitumoral efficacy of CPT nanoparticles was tested on a 9L rat glioma model.

The purpose of this study was to evaluate the in vivo efficacy of CPT loaded cyclodextrins or polymeric nanoparticles and to compare the antitumor activity of CPT incorporated in different nanoparticle formulations being cyclodextrin or polymer-based. Solubilization and stabilization of CPT were realized through drug encapsulation into nanoparticulate systems of amphiphilic cyclodextrins, PLGA and PCL. For this purpose, two approaches for the stabilization of CPT have been combined. Inclusion complex formation with cyclodextrin derivatives and nanoparticle encapsulation have been used to deliver CPT in its stable form for all nanoparticle formulations.

\section{Materials and methods}

\subsection{Materials}

20S-Camptothecin (CPT, MW: $348.36 \mathrm{~g} / \mathrm{mol}$ ) was purchased from Sigma-Aldrich (St. Louis, USA). Amphiphilic $\beta$-cyclodextrin derivative $\beta$-CDC6 (MW: $2506 \mathrm{~g} / \mathrm{mol}$, calculated HLB value: 8.9 ), modified on the secondary face, and 6-O-Capro- $\beta-\mathrm{CD}$ (MW: $1820 \mathrm{~g} / \mathrm{mol}$, calculated HLB value: 11.1 ), modified on the primary face with $6 \mathrm{C}$ aliphatic chains, were synthesized, purified and characterized as reported previously (Memisoglu et al., 2002). (2-Hydroxypropyl)- $\beta$-cyclodextrin (HP- $\beta$-CD) (MW: $1396 \mathrm{~g} / \mathrm{mol}$ ), poly- $\varepsilon$-caprolactone (PCL) (MW: $14,000 \mathrm{D})$ and Poly(lactide-coglycolide) (PLGA 50:50) (MW: 40,000-75,000 D) were purchased from Sigma-Aldrich (St. Louis, USA). Pluronic F68 was obtained from ICI Surfactants (Clamart, France). Acetone was purchased from Riedel-de Haen (Seelze, Germany). Absolute alcohol was purchased from Grup Deltalar (Ankara, Turkey). Tween 80 was obtained from Merck-Schuchardt (Hohenbrunn, Germany). Ultra pure water (Milipore Simplicity 185, France) was used to prepare nanoparticles. All organic solvents were of high performance liquid chromatography (HPLC) grade and were used without further purification.

\subsection{Methods}

\subsubsection{Preparation of inclusion complexes}

2.2.1.1. CPT: $\beta-C D C 6$ and $C P T: 6-0-C a p r o-\beta-C D$ complexes. CPT: $\beta-$ CDC6 and CPT:6-O-Capro- $\beta-C D$ inclusion complexes were prepared in a water/ethanol system using co-lyophilization technique (Fessi et al., 1998). 1:1 molar ratio (drug:CD) complexes were studied. Fixed quantities of CPT and the amphiphilic cyclodextrin $(\beta-\mathrm{CDC} 6$ or $6-\mathrm{O}-\mathrm{Capro}-\beta-\mathrm{CD})$ were dissolved in ethanol and added to a 2 fold volume of water. The system was left to equilibrate under constant stirring for 7 days at room temperature. Ethanolic phase was completely evaporated under vacuum (Buchi R-3000, Switzerland) and the aqueous suspension was lyophilized (Heto Power Dry PL 3000, Denmark) and stored as powder.

2.2.1.2. CPT:HP- $\beta-C D$ complex. The inclusion complex of CPT with $\mathrm{HP}-\beta-\mathrm{CD}$ in a $1: 1$ molar ratio was prepared according to the co-lyophilization technique (Memisoglu et al., 2002). CPT and cyclodextrin were dissolved in appropriate molar ratio in water. The system was left to equilibrate under constant stirring for 7 days at room temperature. At the end of equilibrium time, the dispersion was filtered and filtrate containing soluble CPT:HP- $\beta-C D$ complex (1:1) was lyophilized using a Heto-Holten A/S Lyolab Freeze Dryer (Allerod, Denmark) to obtain the complex in dry powder form.

\subsubsection{Preparation of CPT-loaded amphiphilic $\beta$-cyclodextrin nanoparticles}

Nanoparticles were prepared according to the nanoprecipitation method introduced by Fessi et al. (1998) and further modified (Skiba et al., 1996) to prepare the nanoparticles directly from pre-formed inclusion complexes of CPT and cyclodextrins. The organic phase $(0.8 \mathrm{~mL})$, consisting of $1 \mathrm{mg}$ of CPT:amphiphilic $\beta-C D$ inclusion complex dissolved in absolute alcohol was prepared and $0.2 \mathrm{~mL}$ of CPT solution in absolute alcohol was added to this organic phase. This solution was added at room temperature under constant stirring to $2 \mathrm{~mL}$ of the aqueous phase consisting only of ultrapure water. After stirring for $30 \mathrm{~min}$ at room temperature, the organic solvent was evaporated under vacuum and the nanoparticle dispersion was concentrated to the desired volume ( $2 \mathrm{~mL}$ ). 6-O-Capro- $\beta$-cyclodextrin nanoparticle dispersion $(1.44 \mu \mathrm{g} / 60 \mu \mathrm{L})$ was evaporated until $1 \mathrm{~mL}$ and two-fold concentrated 6-O-Capro- $\beta$-cyclodextrin nanoparticle dispersion $(2.88 \mu \mathrm{g} / 60 \mu \mathrm{L})$ was obtained. 


\subsubsection{Preparation of CPT-loaded polymeric nanoparticles}

The nanoparticles were prepared by nanoprecipitation method (Govender et al., 1999; Cirpanli et al., 2010). Briefly, $75 \mathrm{mg}$ of polymer (PLGA or PCL) were dissolved in $5 \mathrm{~mL}$ of acetone. This organic phase was poured into deionized water $(15 \mathrm{~mL}$ for PLGA, $10 \mathrm{~mL}$ for PCL nanoparticles) containing $75 \mathrm{mg}$ of Pluronic F-68 and $2.5 \mathrm{mg}$ CPT:HP- $\beta-C D$ inclusion complex with moderate stirring at room temperature. Nanoparticles were immediately formed, and acetone was then removed from the colloidal suspension by rotoevaporation under reduced pressure and nanosphere dispersion was obtained. CPT concentration of PLGA and PCL nanoparticles was $0.052 \mu \mathrm{g} / 60 \mu \mathrm{L} \mu \mathrm{g}$ and $0.042 \mu \mathrm{g} / 60 \mu \mathrm{L}$, respectively.

\subsubsection{Characterization of nanoparticles}

Particle size distributions (mean diameter ( $\mathrm{nm}$ ), polydispersity index) of nanoparticles were determined by Photon Correlation Spectroscopy (PCS) with a Malvern Zetasizer Nano-ZS (Malvern Instruments, Malvern, UK). Measurements were realized in triplicate at a $90^{\circ}$ angle at $25^{\circ} \mathrm{C}$ under suitable dilution conditions (Cirpanli et al., 2009).Zeta potential of nanoparticle dispersions was measured in $\mathrm{mV}$ by Malvern Zetasizer Nano-ZS (Malvern Instruments, Malvern, UK) in triplicate. Zeta potential of nanoparticles was measured in aqueous dispersion. Measurements were realized in triplicate at a $120^{\circ}$ angle at $25^{\circ} \mathrm{C}$. A SEM (Jeol-SEM ASID-10 Device in $80 \mathrm{kV}$, Japan) was used to evaluate surface characteristics of the nanoparticles (Cirpanli et al., 2009).

Loaded drug quantity was determined according to the following procedure: unbound drug was separated by centrifugation (Hermle Z-323 K, Germany) at $5000 \mathrm{rpm}$ for $15 \mathrm{~min}$. Supernatant was then collected and lyophilized and the resulting powder containing the loaded nanoparticles was dissolved in dimethylsulfoxide to obtain a clear solution and analyzed by HPLC (Agilent 1100, Germany).

Drug loading values were expressed in terms of entrapped drug quantity, entrapment efficiency and the associated drug percentage. Entrapped drug quantity is the exact drug concentration $(\mu \mathrm{g})$ found per nanoparticle batch. The following formulas were used to calculate entrapment efficiency and associated drug percentage, respectively (Cirpanli et al., 2009):

associated drug $(\%)=\frac{\text { determined CPT quantity }(\mu \mathrm{g})}{\text { initial CPT quantity }(\mu \mathrm{g})} \times 100$

Release profiles of CPT from nanoparticle formulations were determined in $100 \mathrm{~mL}$ of isotonic PBS ( $\mathrm{pH} \mathrm{7.4)}$ ) containing $0.1 \%$ Tween 80 providing sink conditions in a thermostated shaker bath system (Memmert, Schwabach, Germany) at $37^{\circ} \mathrm{C}$ with the dialysis technique (Spectra/Por Cellulose Ester Membrane MWCO: 100,000 Da, Spectrum Labs, Rancho Dominguez, CA). At predetermined time intervals, $1 \mathrm{~mL}$ samples were withdrawn from the system and replaced with equal volume of fresh release medium maintained at the same temperature (Cirpanli et al., 2009). The released amount of CPT was assayed for lactone and carboxylate forms by HPLC as described above.

\subsubsection{Animal study}

2.2.5.1. Animals and anesthesia. Animal care was carried out in strict accordance to the French Ministry of Agriculture regulations. 150-175 g, 10-11-week-old, female, syngeneic Fischer F344 female rats were obtained from Charles River Laboratories France (L'Arbresle, France). The animals were anesthetized with an intraperitoneal injection of $0.75-1.5 \mathrm{~mL} / \mathrm{kg}$ of a solution containing $2 / 3$ ketamine $(100 \mathrm{mg} / \mathrm{mL})$ (Clorketam ${ }^{\circledR}$, Vétoquinol, Lure, France) and $1 / 3$ xylazine $\left(20 \mathrm{mg} / \mathrm{mL}\right.$; Rompun ${ }^{\circledR}$, Bayer, Puteaux, France).

2.2.5.2. Cell culture and cell implantation. Rat gliosarcoma 9L cells were purchased from the European Collection of Cell Culture (Sal- isbury, UK, No. 94110705). The cells were grown at $37^{\circ} \mathrm{C}, 5 \% \mathrm{CO}_{2}$ in Dulbecco's modified Eagle medium with glucose and L-glutamine (BioWhittaker, Verviers, Belgium) containing 10\% foetal calf serum (FCS; BioWhittaker) and $1 \%$ antibiotic and antimycotic solution (Sigma, Saint-Quentin Fallavier, France).

A cultured tumor monolayer was detached with trypsin-ethylenediamine tetraacetic acid then washed twice with Eagle's minimal essential medium without FCS or antibiotics. The cells were counted and resuspended. The final concentration was of $10^{3}$ 9L cells $/ 10 \mu \mathrm{L}$. This cell suspension was injected into the rat striatum at a flow rate of $2 \mu \mathrm{L} / \mathrm{min}$ using a $10 \mu \mathrm{L}$ syringe (Hamilton ${ }^{\circledR}$ glass syringe 700 series $\mathrm{RN}$ ) with a $32 \mathrm{G}$ needle (Hamilton ${ }^{\circledR}$ ) in intracranial implantation.

For that purpose, rats were immobilised in a stereotaxic head frame (Lab Standard Stereotaxic; Stoelting, Chicago, IL). A sagittal incision was made through the skin, and a burr hole was drilled into the skull with a twist drill. The cannula coordinates were $1 \mathrm{~mm}$ posterior from the bregma, $3 \mathrm{~mm}$ lateral from the sagittal suture and $5 \mathrm{~mm}$ below the dura (with the incisor bar set at $0 \mathrm{~mm}$ ) using a small dental drill. The needle was left in place for an additional $5 \mathrm{~min}$ to avoid expulsion of the suspension from the brain during removal of the syringe, which was withdrawn very slowly with a rate of $0.5 \mathrm{~mm} / \mathrm{min}$.

2.2.5.3. MRI. On the 5th days of the experiment, magnetic resonance images were collected from the rats to confirm tumor formation. MRI was performed with a Bruker Avance DRX 300 (Germany) apparatus equipped with a vertical superwide-bore magnet of 7T. Rapid qualitative T2-weighted images were obtained using rapid acquisition with relaxation enhancement (RARE) sequence $\left(\mathrm{TR}=2000 \mathrm{~ms}\right.$; mean echo time $\left(T_{\mathrm{em}}\right)=31.7 \mathrm{~ms}$; RARE factor $=8 ; \mathrm{FOV}=3 \mathrm{~cm} \times 3 \mathrm{~cm}$; matrix $128 \times 128$; nine contiguous slices of $1 \mathrm{~mm}$, eight acquisitions). MR imaging was performed under isofluroane/oxygen anesthesia.

2.2.5.4. Convection enhanced delivery procedure. On day 6 following cell implantation, $60 \mu \mathrm{L}$ of the nanoparticle suspension was injected by CED at the same coordinates as the tumor cells were. CED was performed with an osmotic pump PHD 2000 infusion (Harvard Apparatus) by controlling a $0.5 \mu \mathrm{L} / \mathrm{min}$ rate for $2 \mathrm{~h}$. Infusions were performed at the depth of $5 \mathrm{~mm}$ from the brain surface using a $10 \mu \mathrm{L}$ Hamilton $^{\circledR}$ syringe with a $32 \mathrm{G}$ needle. This syringe was connected to a $100 \mu \mathrm{L}$ Hamilton $22 \mathrm{G}$ syringe containing the product (Harvard Apparatus, Les Ulis, France) through a cannula (CoExTMPE/PVC tubing, Harvard Apparatus). Fifty-three rats with 9L tumor cells were randomized into six experimental groups. The groups were as follows (Hatefi and Amsden, 2002): control group without CED but with the same anesthetized scheme $(n=7)$; (2) CED group of 6-O-Capro- $\beta$-CD nanoparticles $(n=16)$, (3) CED group of $6-0-C a p r o-\beta-C D$ high concentration nanoparticles $(n=6)$; (4) CED group of $\beta$-CDC6 nanoparticles $(n=8)$, (5) CED group of PLGA nanoparticles $(n=8)$ and (6) CED group of PCL nanoparticles $(n=8)$.

2.2.5.5. Statistical analysis. The Kaplan-Meier method was used to plot animal survival. Statistical significance was calculated using the log-rank test (Mantel-Cox Test). StatView software version 5.0 (SAS Institute) was used for that purpose, and tests were considered as significant with $p$ values of less than 0.05 .

\section{Results and discussion}

Topoisomerase I plays a crucial role in the normal replication of DNA. The cytotoxic effect of CPT can be explained by DNA-topoisomerase I complex. CPT binds to and stabilizes this complex that forms during replication. CPT possesses cytotoxic effects beyond those exerted while cells are in S-phase. In this 
Table 1

Particle size, zeta potential and drug loading values of nanoparticles.

\begin{tabular}{|c|c|c|c|c|c|c|}
\hline Formulations & $\begin{array}{l}\text { Mean diameter } \\
(\mathrm{nm}) \pm \text { S.D. }\end{array}$ & PI & $\begin{array}{l}\text { Zeta potential } \\
(\mathrm{mV}) \pm \text { S.D. }\end{array}$ & $\begin{array}{l}\text { Entrapped quantity } \\
(\mu g) \pm \text { S.D. }\end{array}$ & $\begin{array}{l}\text { Entrapment } \\
\text { efficiency ( } \pm \text { S.D.) }\end{array}$ & $\begin{array}{l}\text { Associated drug \% } \\
\text { ( } \pm \text { S.D.) }\end{array}$ \\
\hline CPT: $\beta$-CDC6 nanoparticles & $116 \pm 29$ & 0.16 & $-22 \pm 0.7$ & $28 \pm 2$ & $32 \pm 4$ & $9 \pm 1$ \\
\hline CPT:6-O-Capro- $\beta$-CD nanoparticles & $281 \pm 15$ & 0.26 & $-13 \pm 0.9$ & $48 \pm 4$ & $57 \pm 11$ & $13 \pm 3$ \\
\hline PLGA nanoparticles & $187 \pm 9$ & 0.08 & $-0.06 \pm 1$ & $13 \pm 0.1$ & $6.6 \pm 0.1$ & $2.6 \pm 0.03$ \\
\hline PCL nanoparticles & $274 \pm 0.8$ & 0.07 & $-19 \pm 0.2$ & $7.2 \pm 0.5$ & $3.6 \pm 0.6$ & $1.4 \pm 0.2$ \\
\hline
\end{tabular}

study, its physiological stability and insolubility problems can be solved.

Particle size and zeta potential values of nanoparticles are exposed in Table 1 . Nanoparticles are around $120-280 \mathrm{~nm}$ which suggests favorable properties for injectable systems and possibility to target cancer tissues via EPR effect (Vonarbourg et al., 2006). CPT loaded nanoparticles display zeta potential values varying between 0 and $-20 \mathrm{mV}$. Zeta potential is a function of the surface charge of colloidal dispersions and commonly used to predict dispersion stability. SEM photographs of the nanoparticles revealed that the surfaces were smooth and spherical (data not shown) (Cirpanli et al., 2010). Drug loading values of camptothecin are seen in Table 1 in terms of entrapped drug quantity, entrapment efficiency, and associated drug percentage. Data suggest that amphiphilic cyclodextrin nanoparticles have higher loading capacity than polymeric nanoparticles. Entrapped quantity values were $28 \mu \mathrm{g}$ and $48 \mu \mathrm{g}$ for $\beta$-CDC6 and 6-O-Capro- $\beta$-CD nanoparticles, respectively. These results confirm that drug inclusion may be facilitated by leaving the primary or secondary face unmodified and thus reducing the steric hindrance and leaving the wider side of the cavity open for the entrance of CPT totally or partially. On the other hand, preparation of polymeric nanoparticles from preformed inclusion complexes of CPT and HP- $\beta-C D$ resulted in lower drug loading values as a result of the highly hydrophilic character of drug:cyclodextrin complex (Cirpanli et al., 2009). Entrapped quantity values were $13 \mu \mathrm{g}$ for PLGA and $7 \mu \mathrm{g}$ for PCL nanoparticles.

CPT loaded nanoparticles were incubated in phosphate buffered saline solutions ( $\mathrm{pH} 7.4$ ) containing $0.1 \%$ Tween 80 , at $37^{\circ} \mathrm{C}$. At predetermined intervals, the supernatant fractions were removed and the medium was replenished to maintain the sink conditions. The amount of drug in the supernatant samples was quantified by HPLC and the cumulative percentages of the loaded drug released in the supernatant fractions were plotted versus time. 6-O-Capro$\beta-C D$ nanoparticles exhibited an initial release of approximately $158 \mathrm{ng} / \mathrm{mL}$, and the remaining CPT was liberated with a controlled release profile over $288 \mathrm{~h}$. The more vigorous burst effect in the case of $\beta$-CDC6 nanoparticles resulted in $145 \mathrm{ng} / \mathrm{mL}$ cumulative release of CPT after $5 \mathrm{~h}$. The major significance of the CPT release profiles from both $\beta$-CDC6 and 6-O-Capro- $\beta-C D$ nanoparticles is the fact that CPT was maintained in its active lactone form and released to the physiological medium for more than 12 days for 6 -O-Capro- $\beta$ CD nanoparticles and 6 days for $\beta$-CDC6 nanoparticles. It can be seen that PLGA nanoparticles liberate the drug in a considerably slower release profile than PCL nanoparticles. For PLGA nanoparticles, $12 \mathrm{ng} / \mathrm{mL}$ of the drug was released within $1 \mathrm{~h}$. Complete release of CPT lactone form was realized within a period of more than $48 \mathrm{~h}$. For PCL nanoparticles, $13 \mathrm{ng} / \mathrm{mL}$ of the drug was released within $3 \mathrm{~h}$. CPT lactone form release was completed in $24 \mathrm{~h}$. CPT polymer interaction and hydrophilicity of the polymers are believed to play an important role in release rate of CPT from PLGA or PCL nanoparticles.

In the last decade, in vivo MR imaging techniques have become established tools in animal experimentation. The use of MRI for the characterization of animal models offers some advantages. It is non-invasive imaging modality and a sensitive tool for the detection of tumor tissue. Antitumor efficacy of CPT loaded cyclodextrin
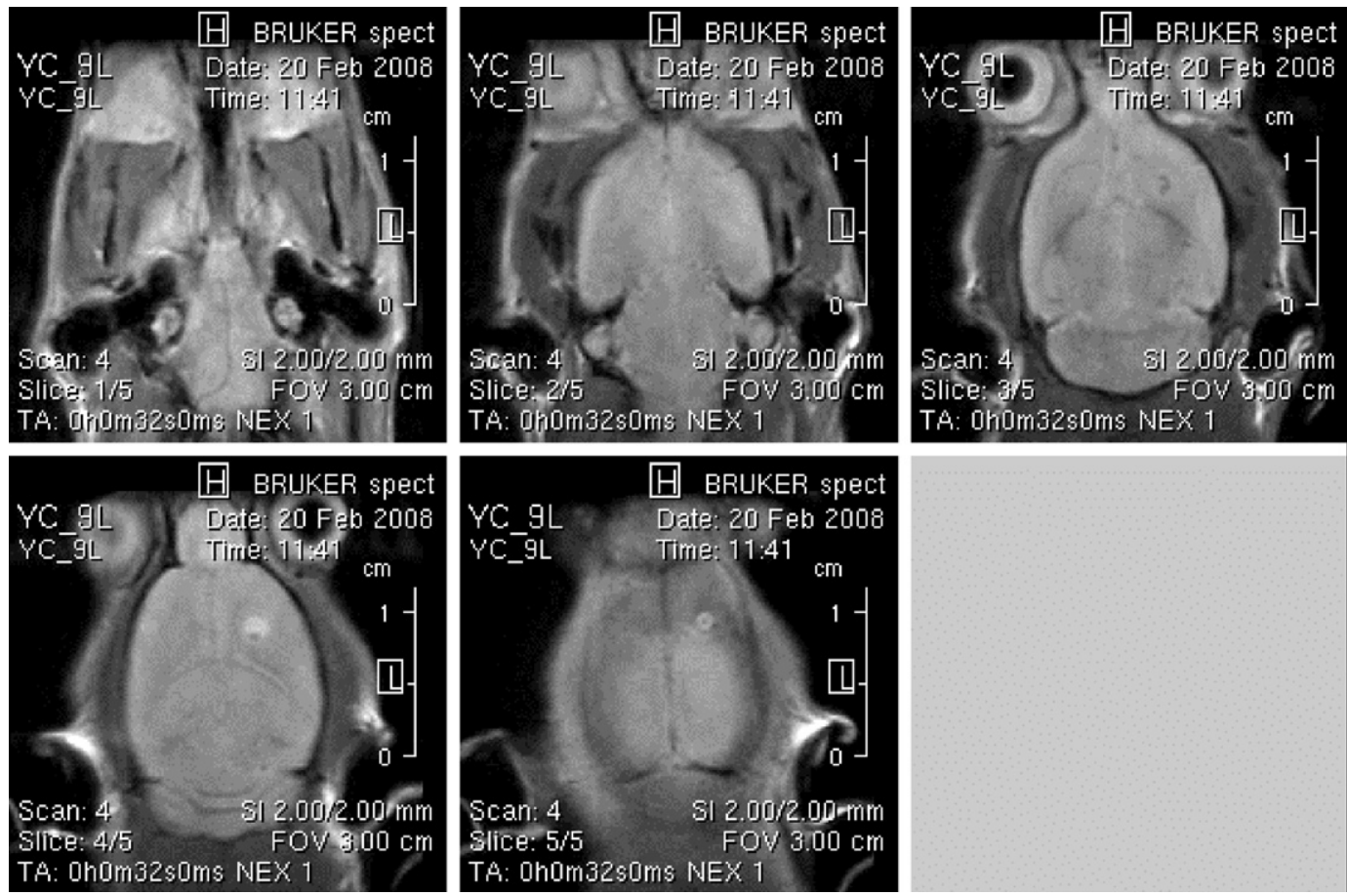

Fig. 2. Magnetic resonance image sample of tumors 5 days after 9L cell implantation. 


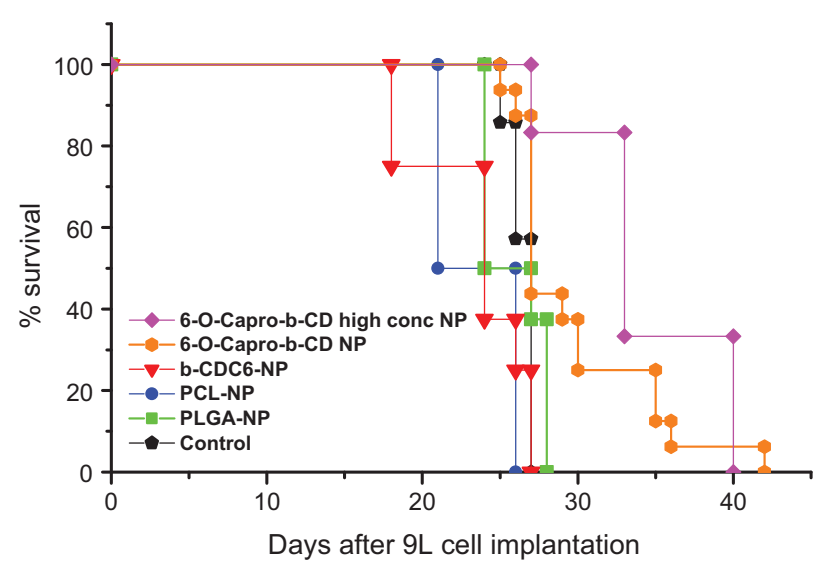

Fig. 3. Graph of Kaplan-Meier survival curve associated with treatment of rat bearing 9L glioma with single CED infusion of $6-0-C a p r o-\beta-C D, \beta-C D C 6$, PLGA, PCL and high concentration of 6-O-Capro- $\beta$-CD nanoparticles.

nanoparticles was evaluated on a 9L rat brain tumor model after CED of the particles. The 9L gliosarcoma cell line has proven to be promising for tumor induction (Allard et al., 2008, 2009b, 2010). Tumor formation in the brain was evaluated by MRI images. All the animals were tested positively for tumor presence 5 days after glioma cell injection. Fig. 2 shows typical MR images of the brain tumor. The tumors appeared as homogeneously in the left striatum of the rat brains, where the 9L gliosarcoma cells were planted for tumor induction.

The effect of CPT nanoparticles on rat survival was examined in this study and the results of these experiments are shown in Fig. 3. In the first set of in vivo experiments, the 4 nanoparticle formulations were evaluated with statistically significant number of animals in each group being at least 6 . Then in a second experiment, 6-O-Capro- $\beta$-CD group which gave the best results was reevaluated with another set of animals to verify the antitumoral activity data. In the third step of the experiments, this formulation was given in twice concentrated form to see if this effect was concentration-dependent. Therefore, the in vivo evaluation consists of three consecutive steps which follow each other according to the data obtained during the studies. All non-treated rats died within 27 days with a median survival of 26 days (Table 2 ). In our study, neither CPT: $\beta$-CDC6 nor CPT:PCL nanoparticles had a significant effect on the growth or lethality of the 9L gliomas, since the median survival time was about 23.5 and 24 days for these formulations respectively. Rats, which received a CED infusion of CPT:PLGA nanoparticles, died within 28 days postimplantation, the median survival was 25.5 days and log rank test results show that there was no significant difference with the control group $(p=0.4772)$.

On the other hand, rats treated with CPT:6-O-Capro- $\beta-C D$ nanoparticles died within 42 days post-implantation; their median survival was 27 days with an increased median survival time (ISTmedian) of $3.8 \%$. A statistically significant difference was observed with the control group $(p=0.0064)$. Moreover, the experiments established that rat median survival was improved significantly for concentrated CPT:6-O-Capro- $\beta-C D$ nanoparticles compared with the control group $(p=0.0023)$. Animals showed improved survival, a median survival of 33 days and an increase in the median survival time (ISTmedian) of $26.9 \%$ compared to the control group. So, a single CED infusion of 6-O-Capro- $\beta$-cyclodextrin and concentrated 6-O-Capro- $\beta$ cyclodextrin nanoparticles resulted in significantly improved median survival compared with CED of control group. These nanoparticles were considered to be effective because of high drug loading capacities and prolonged release profiles. However, there was no statistical difference between CPT:6-O-Capro- $\beta$ CD nanoparticle group and concentrated CPT:6-O-Capro- $\beta-C D$ nanoparticle group $(p=0.1925)$, in spite of the presence of two long-term survivors in concentrated 6-O-Capro- $\beta$-cyclodextrin nanoparticle group. In conclusion, 6-O-Capro- $\beta$-cyclodextrin nanoparticles both in single infusion and in concentrated form resulted in significantly longer survival when compared to other nanoparticle formulations. This is believed to result from both favorable entrapment efficiency of CPT in 6-O-Capro- $\beta$ cyclodextrin nanoparticles and prolonged drug release profile which was found to be up to 12 days upon single administration.

Several groups have reported about improved convection and pharmacological properties of camptothecins, which are known to be active against malignant glioma, by encapsulation into liposomes (Krauze et al., 2007; Saito et al., 2006; Yamashita et al., 2007).

Yamashita et al. (2007) evaluated a combination of nanoliposomal topotecan and pegylated liposomal doxorubicin to enhance efficacy on U87MG tumor model and to establish a CED treatment capable of improving survival from malignant brain tumors. Their results showed that animals in the control group had a median survival of less than 30 days; on the other hand the combination group experienced a median survival of more than 90 days. They concluded that these systems may be an effective treatment option for malignant gliomas.

Noble et al. (2006) evaluated that CPT-11 loaded liposome for brain tumor treatment. In the intracranial U87 glioma xenograft model, a single CED infusion of nanoliposomal CPT-11 resulted in significantly improved median survival compared with CED of control liposomes or free drug. They concluded that CED of nanoliposomal CPT-11 greatly prolonged tissue residence while also substantially reducing toxicity, resulting in a highly effective treatment strategy in preclinical brain tumor models.

Grahn et al. (2009) developed non-PEGylated liposomal formulation which encapsulated topotecan. The results showed that, in a U87MG intracranial rat xenograft model, CED regimen of the liposome greatly increased median survival. A two-dose CED regimen of topoCED co-infused with gadoCED greatly increased median overall survival at dose levels of $0.5 \mathrm{mg} / \mathrm{mL}$ (29.5 days) and $1.0 \mathrm{mg} / \mathrm{mL}$ (33.0 days) vs. control (20.0 days; $P<0.0001$ for both comparisons).

Table 2

Descriptive data from in vivo study.

\begin{tabular}{|c|c|c|c|c|c|}
\hline Formulations & $n$ & Median survival time (days) & Range (days) & $\begin{array}{l}\text { Increased } \\
\text { survival time } \\
\text { median }(\%)\end{array}$ & $\begin{array}{l}p \text {-Values } \\
\text { versus control }\end{array}$ \\
\hline 6-O-Capro- $\beta$-CD nanoparticles & 16 & 27 & $25-42$ & 3.8 & 0.0064 \\
\hline $6-O-C a p r o-\beta-C D$ high concentration nanoparticles & 6 & 33 & $27-40$ & 26.9 & 0.0023 \\
\hline$\beta$-CDC6 nanoparticles & 8 & 24 & $18-27$ & 0 & 0.1926 \\
\hline PLGA nanoparticles & 8 & 25.5 & $24-28$ & 0 & 0.4772 \\
\hline PCL nanoparticles & 8 & 23.5 & $21-27$ & 0 & 0.0619 \\
\hline Control & 7 & 26 & $25-27$ & - & - \\
\hline
\end{tabular}




\section{Conclusion}

Entrapment efficiency and associated drug percentage were significantly higher $(p<0.05)$ for $6-O-C a p r o-\beta-C D$ when compared to the other formulations. 6-O-Capro- $\beta$-CD nanoparticle formulation showed a significant controlled release profile. In vitro release data indicate that it is possible to avoid burst effect and extend the release profile of nanoparticles to 12 days. In addition to the in vitro studies, in vivo studies showed that $6-0-C a p r o-\beta-C D$ cyclodextrin and concentrated 6-O-Capro- $\beta-\mathrm{CD}$ cyclodextrin nanoparticles significantly modified the growth or lethality of the 9L glioma tumors.

Therefore, it was demonstrated in this study a new nanoparticulate delivery system for CPT can be effective in vivo. CPT loaded cyclodextrin nanoparticles emerge as promising delivery systems for cancer therapy which are demonstrated to be safe, effective and stable formulations for delivery of CPT. These findings show that convection enhanced delivery (CED) of 6-O-Capro- $\beta$-CD cyclodextrin nanoparticles appear to be safe and potent antitumor system for treating malignant gliomas.

\section{Acknowledgements}

The authors wish to acknowledge the financial support from TÜBITAK-BDP, TÜBITAK research project SBAG-HD-66, and Hacettepe University Research Fund Project 0202301005 and ERASMUS for the mobility of Ph.D. student Yasemin Cirpanli. They also would like to thank Pierre Legras (Animalerie HospotaloUniversitaire, CHU, Angers, France) for technical support.

\section{References}

Allard, E., Passirani, C., Garcion, E., Vessieres, A., Jaouen, G., Benoit, J.P., 2008. Lipid nanocapsules loaded with an organometallic tamoxifen derivative as a novel drug-carrier system for experimental malignant gliomas. Journal of Controlled Release 130 (2), 146-153.

Allard, E., Passirani, C., Benoit, J.P., 2009a. Convection-enhanced delivery of nanocarriers for the treatment of brain tumors. Biomaterials 30, 2302-2318.

Allard, E., Huynh, N.T., Vessieres, A., Jaouen, G., Benoit, J.P., Passirani, C., 2009b. Dose effect activity of ferrocifen-loaded lipid nanocapsules on a 9L-glioma model. International Journal of Pharmaceutics 379 (2), 317-323.

Allard, E., Jarnet, D., Vessieres, A., Vinchon-Petit, S., Jaouen, G., Benoit, J.P., Passirani, C., 2010. Local delivery of ferrociphenol lipid nanocapsules followed by external radiotherapy as a synergistic treatment against intracranial 9L glioma. Pharmaceutical Research 27 (1), 56-64.

Berrada, M., Serreqi, A., Dabbarh, F., Owusu, A., Gupta, A., Lehnert, S., 2005. A novel non-toxic camptothecin formulation for cancer chemotherapy. Biomaterials 26 , 2115-2120.

Bilensoy, E., 2008. Nanoparticulate delivery systems based on amphiphilic cyclodextrins. Journal of Biomedical Nanotechnology 4, 293-303.

Brewster, M.E., Loftsson, T., 2007. Cyclodextrins as pharmaceutical solubilizers. Advanced Drug Delivery Reviews 59, 645-666.
Cirpanli, Y., Bilensoy, E., Dogan, A.L., Calis, S., 2009. Comparative evaluation of polymeric and amphiphilic cyclodextrin nanoparticles for effective camptothecin delivery. European Journal of Pharmaceutics and Biopharmaceutics 73 (1), 82-89.

Cirpanli, Y., Bilensoy, E., Dogan, A.L., Calis, S., 2010. Development of polymeric and cyclodextrin nanoparticles for camptothecin delivery. In: 11th European Symposium on Controlled Drug Delivery, Egmond aan Zee, The Netherlands, April 7-9, 2010.

Fessi, H., Devissaguet, J.P., Thies, C., 1998. Process for the preparation of dispersible colloidal systems of a substance in the form of nanospheres. US Patent $5,118,528$

Govender, T., Stolnik, S., Garnett, M.C. Illum, L., Davis, S.S., 1999. PLGA nanoparticles prepared by nanoprecipitation: drug loading and release studies of a water soluble drug. Journal of Controlled Release 57, 171-185.

Grahn, A.Y., Bankiewicz, K.S., Dugich-Djordjevic, M., Bringas, J.R., Hadaczek, P. Johnson, G.A., Eastman, S., Luz, M., 2009. Non-PEGylated liposomes for convection-enhanced delivery of topotecan and gadodiamide in malignant glioma: initial experience. Neuro-Oncology 95, 185-197.

Gralow, J., Ozols, R.F., Bajorin, D.F., Cheson, B.D., Sandler, H.M., Winer, E.P., 2008 Clinical cancer advances 2007: major research advances in cancer treatment prevention, and screening - a report from the American Society of Clinical Oncology. Journal of Clinical Oncology 26, 313-325.

Hatefi, A., Amsden, B., 2002. Camptothecin delivery methods. Pharmaceutical Research 19, 1389-1399.

Krauze, M.T., Noble, C.O., Kawaguchi, T., et al., 2007. Convection enhanced delivery of nanoliposomal CPT-11 (irinotecan) and PEGylated liposomal doxorubicin (Doxil) in rodent intracranial brain tumor xenografts. Neuro-oncology 9, 393-403.

Kunii, R., Onishi, H., Machida, Y., 2007. Preparation and antitumor characteristics of PLA/(PEG-PPG-PEG) nanoparticles loaded with camptothecin. European Journal of Pharmaceutical Sciences 67, 9-17.

Loftsson, T., Duchene, D., 2007. Cyclodextrins and their pharmaceutical applications. International Journal of Pharmaceutics 329, 1-11.

Memisoglu, E., Bochot, A., Sen, M., Charon, D., Duchene, D., Hincal, A.A., 2002. Amphiphilic $\beta$-cyclodextrins modified on the primary face: synthesis, characterization and evaluation of their potential as novel excipients in the preparation of nanocapsules. Journal of Pharmaceutical Sciences 91, 1214-1224.

Noble, C.O., Krauze, M.T., Drummond, D.C., Yamashita, Y., Saito, R., Berger, M.S. Kirpotin, D.B., Bankiewicz, K.S., Park, J.W., 2006. Novel nanoliposomal CPT-11 infused by convection-enhanced delivery in intracranial tumors: pharmacology and efficacy. Cancer Research 66, 2801-2806.

Rothenberg, M.L., 1997. Topoisomerase I inhibitors: review and update. Annals of Oncology 8, 837-855.

Saito, R., Krauze, M.T., Noble, C.O., Drummond, D.C., Kirpotin, D.B., Berger, M.S., Park J.W., Bankiewicz, K.S., 2006. Convection-enhanced delivery of Ls-TPT enables an effective, continuous, low-dose chemotherapy against malignant glioma xenograft model. Neuro-Oncology 8, 205-214.

Skiba, M., Wouessidjewei, D., Puisieux, F., Duchêne, D., Gulik, A., 1996. Characterization of amphiphilic $\beta$-cyclodextrin nanospheres. International Journal of Pharmaceutics 142, 121-124.

Tung, W., Wang, L., D’Souza, M.J., 2003. Evaluation of PLGA microspheres as delivery system for antitumor agent-camptothecin. Drug Development and Industrial Pharmacy 29 (7), 745-756.

Uekama, K., Hirayama, F., Irie, T., 1998. Cyclodextrin drug carrier systems. Chemical Reviews 98, 2045-2076.

Vonarbourg, A., Passirani, C., Saulnier, P., Benoit, J.P., 2006. Parameters influencing the stealthiness of in vivo injectable intravenous nanoparticles. Biomaterials 27 , 4356-4373.

Yamashita, Y., Krauze, M.T., Kawaguchi, T.O., noble, C., Drummond, D.C., Park, J.W. Bankiewicz, K.S., 2007. Convection-enhanced delivery of a topoisomerase inhibitor (nanoliposomal topotecan) and a topoisomerase II inhibitor (pegylated liposomal doxorubicin) in intracranial brain tumor xenografts. Neuro-Oncology 9, 20-28. 